\title{
Breakfast habits among adolescents and their association with daily energy and fish, vegetable, and fruit intake: a community-based cross-sectional study
}

\author{
Shinichi Sugiyama • Masayuki Okuda • \\ Satoshi Sasaki • Ichiro Kunitsugu • Tatsuya Hobara
}

Received: 30 November 2011/Accepted: 31 January 2012/Published online: 18 February 2012

(c) The Japanese Society for Hygiene 2012

\begin{abstract}
Objectives To investigate breakfast eating habits on daily energy and fish, vegetable, and fruit intake in Japanese adolescents.

Methods This study was completed as part of the Shunan Child Health Cohort Study. Two types of questionnaires, one on lifestyle habits and the other a brief-type, selfadministered questionnaire on diet history, were administered to second-year junior high school students $(1,876$ boys and 1,759 girls) in Shunan City, Yamaguchi, Japan. The different breakfast habits were compared using the general linear model and the estimated means and $P$ value for trend were calculated, with energy-adjusted food intake as the dependent variable and body mass index, gender, age, residential areas, and living status as covariates.

Results In both males and females, the proportion of those who ate breakfast irregularly was about $10 \%$. The daily intake of fish, vegetables, and fruit was significantly higher in those who ate breakfast with their guardians than in those who ate breakfast alone $(P$ for trend $<0.01)$. The
\end{abstract}

\section{S. Sugiyama $(\bowtie)$}

Mazda Motor Corporation Hofu Clinic, 888-1 Nishinoura,

Hofu, Yamaguchi 747-0835, Japan

e-mail:ss47264726@gmail.com

\section{Okuda}

Department of Environmental Safety, Graduate School

of Science and Engineering, Yamaguchi University, Ube, Japan

S. Sasaki

Department of Social and Preventive Epidemiology,

School of Public Health, Tokyo University, Tokyo, Japan

I. Kunitsugu $\cdot$ T. Hobara

Department of Public Health, Graduate School of Medicine,

Yamaguchi University, Ube, Japan daily intake of fish, seafood, and vegetables was significantly higher in those who less frequently ate cooked foods for breakfast ( $P$ for trend $<0.01$ ). Those who ate rice more frequently than bread at breakfast had a higher daily intake of fish, seafood, and vegetables ( $P$ for trend $<0.01$ ). Conclusions Eating breakfast with the family, reducing the intake of cooked foods at breakfast, and eating breakfast with rice as a main staple food are suggested to contribute to an improved quality of diet in adolescents.

Keywords Breakfast styles - Daily energy/food intake . Japanese adolescents · Cross-sectional study · Dietary education

\section{Introduction}

The intake of vegetables, fruit, and fish is known to be beneficial for the prevention of chronic diseases. More specifically, the intake of vegetables and fruit has been reported to reduce the risk of cancer, heart disease, stroke, among others [1-3] and the intake of fish to reduce the occurrence of cardiovascular events [4]. The traditional Japanese diet is characterized by rice as the main staple combined with side dishes and miso soup. In addition, the intake of lipids and carbohydrates is relatively low, and beans, seaweeds, and fish, which are not popular in many Western countries, are also regularly consumed [5]. Recently, however, the intake of vegetables and fish has shown a decreasing trend in younger generations [6].

According to the 2008 National Health and Nutritional Survey of Japan, $6.5 \%$ of boys and $5.0 \%$ of girls aged 7-14 years regularly skip breakfast, and these percentages have remained relatively constant over recent years [6]. Also, according to a survey of school children, bread is 
eaten for breakfast by about $38 \%$ of junior high school students, and only $46 \%$ eat breakfast with their parents or guardians [7]. These findings suggest that the traditional Japanese diet with rice as a staple food is changing as the percentage of nuclear families increases and that processed foods, which are inexpensive and easily accessible, are replacing the traditional Japanese diet.

A number of previous investigations addressed differences in food/nutritional intake in the daily diet depending on whether the individual ate breakfast or not, what he/she consumed as a staple food of breakfast, and whether breakfast was eaten alone or with family members. The results of these studies demonstrated that the intake of vegetables and fruits in the daily diet was lower in adolescents who skipped breakfast compared with those who regularly ate it $[8,9]$. A survey of female college students also reported that the intake of vegetables, fruit, and fish in the daily diet tended to be higher among those who more frequently consumed rice than among those who more frequently consumed bread as the staple breakfast food [10]. In addition, intake of healthy foods, such as vegetables and fruit, tended to be higher in children who ate dinner with the family $[11,12]$.

Of adults who regularly skip breakfast, about one-third of males and about one-quarter of females have been reported to have acquired this habit between elementary and high school [6]. The dietary habits established during adolescence are considered to continue into early adulthood [13, 14]. Therefore, it is important to form appropriate dietary habits and eating behavior based on breakfast at puberty for the prevention of lifestyle-related diseases in adulthood. There have been few studies on the relationships between breakfast habits and energy/food intake in the daily diet among adolescents at the age of puberty in Japan. The aim of this study was to clarify the relationships of various factors associated with breakfast with the intake of vegetables, fish, and fruit in the daily diet of second-year junior high school students.

\section{Methods}

Subjects and methods

This investigation was carried out as a cross-sectional study using part of the Shunan Child Health Cohort Study population (2006-2010). Shunan City is located in central Yamaguchi Prefecture. Its southern part is a coastal industrial area, and the northern part is a mountainous area. The total area of the city is about $656 \mathrm{~km}^{2}$, the population was about 153,000 as of January 2011, and the percentage of boys and girls aged 0-14 years in the general population was 14.0 and $12.6 \%$, respectively.
From 2007 to 2009, all 4,118 (1,929 boys and 1,812 girls) second-year junior high school students in Shunan City were surveyed with a questionnaire and blood tests in June and July of each year. The questionnaire was filled in at home by the adolescents themselves or by their parents. Completed questionnaires were obtained from 3,635 adolescents (1,876 boys and 1,759 girls).

\section{Ethical considerations}

The study plan was generated according to the Ethical Guidelines for Epidemiological Research established by the Ministry of Health, Labour and Welfare and the Ministry of Education, Culture, Sports, Science and Technology. The plan was approved in accordance with Article 2 of the reviewing committee's rules for the Institutional Review Board for Clinical Trials for New Drug Application/Clinical Studies, Yamaguchi University Hospital. The researchers analyzed unidentified information. We obtained written informed consent from the participants after providing a written explanation of the study.

\section{Questionnaires}

A 53-item, self-administered questionnaire was used to investigate the eating behavior, lifestyle, perception of the physique, family composition, and medical history, including present condition. The dietary survey was performed using the junior high school/high school version of the brief-type, self-administered diet history questionnaire (BDHQ) [15]. Using the information provided in the dietary survey by the responder, which consisted of answers to 89 questions on the frequency of intake of various food items, cooking methods, and eating behavior during the previous month, we calculated the estimated intake of foods and nutrients using an ad hoc computer algorithm according to a standard procedure-i.e., for most items, dietary intake was calculated on the basis of the reported intake or drinking frequency and the fixed portion size. The validity of the junior high school/high school version of the BDHQ has been verified by a study on the relationships of food intake and blood biomarker levels [16]. The questions on breakfast referred to eating habits during the past month. The question on the frequency of eating breakfast was "Did you eat breakfast?"; the one on the frequency of eating rice was "Did you eat rice, rice gruel, or rice balls for breakfast?"; the one on the frequency of eating bread was "Did you eat bread, toast, corn flakes, cereals, or pancakes for breakfast?" The question on the frequency of eating cooked foods was "Did you eat rice balls, sandwiches, snacks, cup noodles, sweet buns, or deli rolls (curry bread, sausage bread, etc.) that were bought from shops for breakfast?" The questions were answered by selecting one 
answer from five choices: "every day," "4-6 days a week," "2-3 days a week," 1 day a week," and "never." The question of eating breakfast alone or with others was addressed by "Which member of your family do you often eat breakfast with on school days?", and the answers were given by choosing from "with my parents and/or grandparents," "with only brothers or sisters," "alone," and "I do not eat breakfast at home."

\section{Anthropometry}

Body height and weight were measured by school health nurses according to School Health Law. Height was measured to the nearest $0.1 \mathrm{~cm}$ using standard scales with the participant's shoes and socks off. Weight was measured to the nearest $0.1 \mathrm{~kg}$ using calibrated scales while the student was only wearing underclothing. Body mass index (BMI) was calculated as the body weight $(\mathrm{kg})$ divided by the square of the body height (m).

\section{Statistical analysis}

Those who did not answer the questions on breakfast habits, those who had been/were still being treated for physical diseases, such as heart and kidney diseases, those who provided incomplete answers on the BDHQ, those in whom the estimated energy intake was $<500$ or $\geq 5,000 \mathrm{kcal}$, and those for whom the data necessary to calculate the BMI were lacking were excluded from analysis. A total of 3,556 subjects (1,836 boys and 1,720 girls) were ultimately included in the analysis.

The estimated intake calculated from the BDHQ was adjusted for the energy intake (kcal) by the density method and converted to values in grams per 1,000 kcal. Total seafood consumption was calculated as the sum of shrimp, shellfish, and fish (including bones; canned tuna, dried fish, fatty fish, and lean fish) consumed. Total fish consumption was the sum of all fish consumed, including bones, canned tuna, dried fish, fatty fish, and lean fish. Total vegetable consumption was calculated as the sum of green pickled vegetables, other pickled vegetables, salad, green leafy vegetables, cabbage, carrots, Japanese radish, tomatoes, mushrooms, seaweeds, and others that were consumed. The total consumption of green-yellow vegetables was the sum of green leafy vegetables, carrots, and tomatoes consumed. The consumption of other vegetables was considered to be the sum of salad, cabbage, Japanese radish, mushrooms, and others, and that of fruits to be the sum of citrus, Japanese persimmon, strawberry, and others that were consumed.

To distinguish rice- and bread-type breakfasts, the answers to those questions on the frequency of intake of rice and bread were scored as follows: 7 for "every day," 5 for "4-6 days a week," 2.5 for "2-3 days a week," 0.5 for " 1 day a week," and 0 for "never." The score (ranging from -7 to +7 ) was determined by subtracting the points for the bread-type breakfast from those for the rice-type breakfast. Subjects with scores of $-7,-6.5,-5$, -4.5 , and -2.5 points were categorized as "bread type"; those with scores of $-2.0,-0.5,0,+0.5$, and +2.0 points were categorized as "mixed type", and those with scores of $+2.5,+4.5,+5.0,+6.5$, and 7.0 points were categorized as "rice type." The frequency of intake of cooked foods was classified into "2 or more days a week," "1 day a week," and "never."

The estimated population density of the school area was calculated, and the communities in which the subjects lived were classified into urban (population density $\geq 500$ people $/ \mathrm{km}^{2}$ ) or rural (population density $<500$ people $/ \mathrm{km}^{2}$ ) areas [17].

The data on categorical variables were compared by the chi-square test. The energy/food intake was compared between two groups by Student's $t$ test and among three groups using a general linear model. The estimated means were calculated with energy-adjusted food intake used as the dependent variable, and $P$ values for trend was estimated with BMI, gender, age, residential areas, and living status used as covariates. Analysis of the frequency of eating cooked foods for breakfast and the staple food type of breakfast were performed in the 3,251 subjects who answered that they ate breakfast "every day." The analysis of whether the subjects ate breakfast with others or alone was conducted on 3,248 subjects as data on three subjects who answered that they did not "eat breakfast at home" were excluded. Statistical analysis was carried out using SPSS ver. 12.0 (SPSS, Chicago, IL), and $P$ values of $<1 \%$ were regarded as significant.

\section{Results}

Table 1 shows the characteristics of the subjects according to whether or not they ate breakfast. Breakfast was eaten "every day" by $90.1 \%$ of the boys and $92.8 \%$ of the girls. The percentage of subjects who ate breakfast every day was significantly higher among girls and among adolescents who ate breakfast with their parents and/or grandparents. No relationship was observed between whether the subjects ate breakfast regularly or not and residential areas, presence or absence of the mother, or frequency of eating cooked foods. The BMI was significantly lower in those who ate breakfast every day. The intake of fish, vegetables, and fruit in the daily diet was significantly higher in those who ate breakfast every day than in those who did not.

Table 2 shows the relationships between whether the subject ate breakfast with others or alone and the frequency 
Table 1 Characteristics and daily energy/food intake of the subjects according to breakfast habits

Data are presented as the number of adolescents, or as the mean \pm standard deviation (SD)

${ }^{\text {a }}$ Breakfast eating is defined as eating breakfast every day

b Breakfast skipping is defined as eating breakfast on fewer than 7 days per week

c Except for three adolescents who did not eat breakfast at home

d Energy-adjusted values by the density method (g/1,000 kcal)

\begin{tabular}{|c|c|c|c|}
\hline $\begin{array}{l}\text { Characteristics and daily } \\
\text { energy/food intake }\end{array}$ & $\begin{array}{l}\text { Breakfast eaters }^{\mathrm{a}} \\
(n=3,251)\end{array}$ & $\begin{array}{l}\text { Breakfast skippers }{ }^{\mathrm{b}} \\
(n=305)\end{array}$ & $P$ value \\
\hline \multicolumn{4}{|l|}{ Sex } \\
\hline Male & 1,655 & 181 & \multirow[t]{2}{*}{$<0.01$} \\
\hline Female & 1,596 & 124 & \\
\hline \multicolumn{4}{|l|}{ Residential areas } \\
\hline Urban $\left(\geq 500\right.$ persons $\left./ \mathrm{km}^{2}\right)$ & 2,188 & 207 & \multirow[t]{2}{*}{0.90} \\
\hline Rural $\left(<500\right.$ persons $\left./ \mathrm{km}^{2}\right)$ & 1,063 & 98 & \\
\hline \multicolumn{4}{|l|}{ Living status } \\
\hline Living with mother & 3,129 & 287 & \multirow[t]{2}{*}{0.09} \\
\hline Living without mother & 122 & 18 & \\
\hline \multicolumn{4}{|c|}{ Frequency of cooked food intake at breakfast } \\
\hline$\geq 2$ (times/week) & 767 & 88 & \multirow[t]{3}{*}{0.54} \\
\hline 1 (times/week) & 1,005 & 98 & \\
\hline Never (times/week) & 1,479 & 119 & \\
\hline \multicolumn{4}{|l|}{ Eating status at breakfast ${ }^{\mathrm{c}}$} \\
\hline With parents or guardians & 1,488 & 66 & \multirow[t]{3}{*}{$<0.01$} \\
\hline Only with siblings & 1,004 & 89 & \\
\hline Alone & 756 & 121 & \\
\hline Body mass index (BMI; $\mathrm{kg} / \mathrm{m}^{2}$ ) & $19.2 \pm 2.7$ & $20.0 \pm 3.4$ & $<0.01$ \\
\hline Daily energy intake (kcal) & $2,327 \pm 734$ & $2,294 \pm 833$ & 0.50 \\
\hline \multicolumn{4}{|l|}{ Daily food intake $^{\mathrm{d}}(\mathrm{g} / 1,000 \mathrm{kcal})$} \\
\hline Dried and fatty fish & $12.5 \pm 9.2$ & $11.1 \pm 8.0$ & $<0.01$ \\
\hline Total fish & $24.7 \pm 15.4$ & $21.5 \pm 13.6$ & $<0.01$ \\
\hline Total seafood & $31.2 \pm 18.2$ & $27.8 \pm 16.7$ & $<0.01$ \\
\hline Green-yellow vegetables & $34.8 \pm 23.1$ & $27.7 \pm 20.9$ & $<0.01$ \\
\hline Other vegetables & $72.8 \pm 38.2$ & $58.9 \pm 35.6$ & $<0.01$ \\
\hline Total vegetables & $107.6 \pm 56.7$ & $86.7 \pm 52.5$ & $<0.01$ \\
\hline Fruit & $27.7 \pm 24.8$ & $19.3 \pm 17.9$ & $<0.01$ \\
\hline
\end{tabular}

of eating cooked foods, the staple food types, and daily energy/food intake. The frequency of eating cooked foods for breakfast was significantly lower, and the frequency of eating rice type breakfast was significantly higher, in those who ate breakfast with their parents and/or grandparents. The daily intake of fish, vegetables, and fruit was significantly higher in those who ate breakfast with their parents and/or grandparents than in those who ate breakfast alone ( $P$ for trend $<0.01$ ). The energy intake was not related to whether the subject ate breakfast with others or alone.

The intake of total fish, total seafood, green-yellow vegetables, other vegetables, and total vegetables was significantly higher in those who less frequently ate cooked foods for breakfast ( $P$ for trend $<0.01$ ). The intake of energy, dried and fatty fish, and fruit was not related to whether breakfast was eaten with others or alone (Table 3).

The intake of dried and fatty fish, total fish, total seafood, other vegetables, and total vegetables was significantly higher in those who more frequently ate rice for breakfast $(P$ for trend $<0.01$ ). The energy intake, intake of green-yellow vegetables, and intake of fruits were not significantly related to the frequency of eating rice for breakfast (Table 4).

\section{Discussion}

There have been few domestic studies that have independently analyzed the relationships among factors related to the eating of breakfast, such as the frequency of eating breakfast, different staple foods, and cooked foods, and whether the subject ate breakfast with others or alone, with the intake of vegetables, fish, and fruit in the daily diet in adolescents. In this study, the $9.9 \%$ of the boys and $7.2 \%$ of the girls skipped breakfast entirely. Although a straightforward comparison is impossible due to differences in the study area and subjects' age, these frequencies are similar to those found for elementary school children and junior high school student in the National Health and Nutrition Survey, 2009 [7]. Adolescents who ate breakfast with their parents and/or grandparents tended to eat breakfast regularly. Also, those who did not eat breakfast every day, those 
Table 2 Daily energy/food intake and number of adolescents in different categories of cooked food intake and staple food intake at breakfast according to breakfast eating status
Data are presented as the number of adolescents, or as the mean \pm standard error of the mean (SEM)

Except for three adolescents who did not eat breakfast at home

a Adjusted for BMI, gender, age, residential areas and living status

b Energy-adjusted values by the density method $(\mathrm{g} / 1,000 \mathrm{kcal})$

\begin{tabular}{|c|c|c|c|c|}
\hline \multirow[t]{2}{*}{ Daily energy/food intake } & \multicolumn{3}{|c|}{ Social context of eating breakfast $(n=3,248)$} & \multirow[t]{2}{*}{$P$ value } \\
\hline & $\begin{array}{l}\text { With parents or } \\
\text { guardians }(n=1,488)\end{array}$ & $\begin{array}{l}\text { Only with siblings } \\
(n=1,004)\end{array}$ & $\begin{array}{l}\text { Alone } \\
(n=756)\end{array}$ & \\
\hline \multicolumn{5}{|c|}{ Frequency of cooked food intake at breakfast } \\
\hline$\geq 2$ (times/week) & 282 & 270 & 212 & \multirow[t]{3}{*}{$<0.01$} \\
\hline 1 (times/week) & 450 & 312 & 243 & \\
\hline Never (times/week) & 756 & 422 & 301 & \\
\hline \multicolumn{5}{|c|}{ Type of staple food intake at breakfast } \\
\hline Bread-type & 585 & 430 & 331 & \multirow[t]{3}{*}{$<0.01$} \\
\hline Mixed-type & 177 & 144 & 113 & \\
\hline Rice-type & 726 & 430 & 145 & \\
\hline Daily energy ${ }^{\mathrm{a}}$ intake (kcal) & $2,381 \pm 34$ & $2,365 \pm 37$ & $2,408 \pm 38$ & 0.38 \\
\hline \multicolumn{5}{|c|}{ Daily food intake $\mathrm{e}^{\mathrm{a}, \mathrm{b}}(\mathrm{g} / 1,000 \mathrm{kcal})$} \\
\hline Dried and fatty fish & $12.7 \pm 0.5$ & $12.0 \pm 0.5$ & $11.3 \pm 0.5$ & $<0.01$ \\
\hline Total fish & $25.6 \pm 0.8$ & $23.9 \pm 0.8$ & $22.8 \pm 0.9$ & $<0.01$ \\
\hline Total seafood & $32.4 \pm 0.9$ & $30.9 \pm 1.0$ & $29.6 \pm 1.0$ & $<0.01$ \\
\hline Green-yellow vegetables & $34.8 \pm 1.1$ & $31.4 \pm 1.2$ & $30.4 \pm 1.3$ & $<0.01$ \\
\hline Other vegetables & $73.3 \pm 1.9$ & $68.1 \pm 2.0$ & $63.3 \pm 2.1$ & $<0.01$ \\
\hline Total vegetables & $108.6 \pm 2.8$ & $99.6 \pm 3.0$ & $93.7 \pm 3.1$ & $<0.01$ \\
\hline Fruit & $31.3 \pm 1.2$ & $27.6 \pm 1.3$ & $27.8 \pm 1.4$ & $<0.01$ \\
\hline
\end{tabular}

Table 3 Daily energy/food intake according to frequency of cooked food intake at breakfast

\begin{tabular}{|c|c|c|c|c|}
\hline \multirow[t]{2}{*}{ Daily energy/food intake } & \multicolumn{3}{|c|}{ Frequency of cooked food intake at breakfast $(n=3,251)$} & \multirow[t]{2}{*}{$P$ for trend } \\
\hline & $\geq 2$ (times/week) $(n=767)$ & 1 (times/week) $(n=1,005)$ & Never (times/week) $(n=1,479)$ & \\
\hline Daily energy intake ${ }^{\mathrm{a}}(\mathrm{kcal})$ & $2,424 \pm 38$ & $2,398 \pm 36$ & $2,353 \pm 34$ & 0.02 \\
\hline \multicolumn{5}{|c|}{ Daily food intake $e^{a, b}(g / 1,000 \mathrm{kcal})$} \\
\hline Dried and fatty fish & $11.9 \pm 0.5$ & $11.7 \pm 0.5$ & $12.75 \pm 0.4$ & 0.29 \\
\hline Total fish & $23.0 \pm 0.9$ & $23.8 \pm 0.8$ & $25.6 \pm 0.8$ & $<0.01$ \\
\hline Total seafood & $29.8 \pm 1.0$ & $30.5 \pm 1.0$ & $32.5 \pm 0.9$ & $<0.01$ \\
\hline Green-yellow vegetables & $30.2 \pm 1.3$ & $30.9 \pm 1.2$ & $35.3 \pm 1.1$ & $<0.01$ \\
\hline Other vegetables & $61.9 \pm 2.1$ & $66.4 \pm 2.0$ & $75.7 \pm 1.9$ & $<0.01$ \\
\hline Total vegetables & $92.1 \pm 3.1$ & $97.2 \pm 2.9$ & $111.0 \pm 2.8$ & $<0.01$ \\
\hline Fruit & $27.6 \pm 1.4$ & $29.2 \pm 1.3$ & $30.4 \pm 1.2$ & 0.01 \\
\hline
\end{tabular}

Data are presented as the mean \pm SEM

a Adjusted for BMI, gender, age, residential areas, and living status

${ }^{\mathrm{b}}$ Energy-adjusted values by the density method (g/1,000 kcal)

who ate breakfast alone, those who ate bread for breakfast, and those who ate cooked foods for breakfast tended to have a low intake of vegetables and fish in their daily diet, suggesting unhealthy dietary habits.

A study among female college students found that those who ate rice more frequently than bread for breakfast consumed more vegetables and fish [10], which is agreement with the results of our study despite the difference in the subjects' age. The results of our study suggest that a Japanese-style breakfast consisting primarily of rice contributes to a healthier diet. However, the relatively high glycemic index of rice, compared to that of other carbohydrates, such as noodles [18], and a relationship between the intake of polished rice and an increased risk of diabetes in Japanese adult women [19], have been reported as points of caution in the Japanese-style diet. In addition, sodium intake tends to increase in the Japanese diet due to high salt contents in seasonings, such as miso and shoyu. There has been a trend for salt intake to decrease among the Japanese general population, but the daily salt intake of Japanese adults is still high, at around $10.7 \mathrm{~g}$ [6]. Campaigns urging the adoption of health-protecting habits, such as restricting 
Table 4 Daily energy/food intake according to staple food types at breakfast

\begin{tabular}{|c|c|c|c|c|}
\hline \multirow[t]{2}{*}{ Daily energy/food intake } & \multicolumn{3}{|c|}{ Staple food types at breakfast $(n=3,251)$} & \multirow[t]{2}{*}{$P$ for trend } \\
\hline & Bread-type $(n=1,320)$ & Mixed-type $(n=498)$ & Rice-type $(n=1,433)$ & \\
\hline Daily energy intake (kcal) & $2,354 \pm 35$ & $2,409 \pm 42$ & $2,402 \pm 34$ & 0.06 \\
\hline \multicolumn{5}{|c|}{ Daily food intake $\mathrm{a}^{\mathrm{a}, \mathrm{b}}(\mathrm{g} / 1,000 \mathrm{kcal})$} \\
\hline Dried and fatty fish & $11.2 \pm 0.5$ & $11.8 \pm 0.6$ & $13.1 \pm 0.5$ & $<0.01$ \\
\hline Total fish & $22.5 \pm 0.8$ & $23.8 \pm 1.0$ & $26.2 \pm 0.8$ & $<0.01$ \\
\hline Total seafood & $28.9 \pm 0.9$ & $30.8 \pm 1.1$ & $33.4 \pm 0.9$ & $<0.01$ \\
\hline Green-yellow vegetables & $31.8 \pm 1.2$ & $30.9 \pm 1.4$ & $34.0 \pm 1.1$ & 0.10 \\
\hline Other vegetables & $66.1 \pm 1.9$ & $65.4 \pm 2.4$ & $73.7 \pm 1.9$ & $<0.01$ \\
\hline Total vegetables & $97.9 \pm 2.9$ & $96.3 \pm 3.5$ & $107.7 \pm 2.8$ & $<0.01$ \\
\hline Fruit & $30.1 \pm 1.3$ & $28.9 \pm 1.5$ & $28.9 \pm 1.2$ & 0.17 \\
\hline
\end{tabular}

Data are presented as the mean \pm SEM

${ }^{a}$ Adjusted for BMI, gender, age, residential areas and living status

b Energy-adjusted values by the density method (g/1,000 kcal)

the use of seasonings and eating thinner miso soup, have been reported to be effective in reducing the sodium consumption of adults [20], and it has also been suggested that interventional studies of salt-control guidance have reduced the blood pressure [21] and incidence of stroke among the adult Japanese population [22].

A number of studies on the relationships between whether the subjects ate breakfast with their families or not and the intake of specific food groups have been published in Japan. In Japanese elementary school children, the intake of rice, fish, and fruit for breakfast was higher, and the intake of meat and bread for breakfast was lower, among those who ate breakfast with their families [23]. These results are similar to those reported for our study population. A number of overseas studies have also shown that the intake of vegetables and fruit was higher in children who ate dinner with their families, suggesting that the habit of eating together results in a healthier dietary pattern $[11,24]$. Eating alone is considered to lead to a low intake of vegetables and fish in the daily diet because such adolescents are not supervised by guardians and consequently often eat only the foods they like. Also, meals not provided by guardians are often simple and contain less nutritious items, such as frozen and cooked products. Eating meals with guardians is also considered to increase the opportunities to talk about a healthy diet. In more recent times, as each member of the family has become busier, it has become difficult for the family to eat breakfast together. However, for adolescents, the habit of eating meals with the family is clearly related to healthy dietary habits and contents throughout his/her youth [25] and, consequently, parents should seriously consider eating breakfast with their adolescents, even during busy morning hours.

There are a number of possible limitations to the findings of this study. First, in the BDHQ used in the dietary survey in this study, the intake of energy and foods was not recorded directly. We analyzed only food items that were confirmed to be valid. Salt and lipids, which have recently attracted attention, were excluded. Secondly, in this study, whether the subjects ate breakfast was assessed with the question, "Did you eat breakfast?", and the answer was used to estimate the frequency of eating breakfast. However, the appropriateness of this question for verifying whether the subjects ate breakfast or not has not yet been validated. Thirdly, this study was restricted to a particular area, and so the results may differ from those conducted in areas in which the family composition and socioeconomic status differ, as well as the density of convenience stores, such as large cities and sparsely populated areas. Furthermore, the diet of adolescents has been shown to be affected by the socioeconomic indices of the parents, such as educational background, occupation, and income [26, 27], but such factors were not considered in this study. Fourth, in answering the questionnaire, the subjects may have intentionally selected vegetables, fish, and fruit, which are generally considered to be healthy, causing a bias in the results. Despite the above limitations, this study is considered to provide interesting data in that it clarifies the relationship between many factors related to breakfast and the intake of fish, vegetables, and fruit in the daily diet of a large number of adolescents living in a particular area of Japan.

The results of our study suggest that eating breakfast with the family, reducing the intake of cooked foods, and eating a conventional Japanese-style breakfast with rice as a staple food contribute to a healthy diet. Since meals for adolescents are prepared primarily by parents or grandparents, dietary education for parents is also important. Given that vegetables and fruit are more often served at home because the mother is more interested that the child 
in healthy eating habits [28], the evaluation of effective methods for intervention in family meals should be studied. Knowledge of the association between a mother's meal patterns during adolescence and diet quality and meal patterns during young adulthood is considered to be particularly necessary. The government of Japan aims to promote a Japanese-style diet consisting of rice coupled with a variety of side dishes, the habit of families eating together, and improved communication through eating together. We consider that the results of this study are in agreement with the planned government policies on dietary education.

Acknowledgments This study was performed as one of the health promotion activities and supported by a board of education and health promotion center in Shunan City, Yamaguchi, Japan. We are deeply grateful to the health nurses and teachers who assisted in this project.

Conflict of interest The authors declare that there are no conflicts of interest.

\section{References}

1. Bazzano LA, He J, Ogden LG, Loria CM, Vupputuri S, Myers L, et al. Fruit and vegetable intake and risk of cardiovascular disease in US adults: the first National Health and Nutrition Examination Survey Epidemiologic Follow-up Study. Am J Clin Nutr. 2002; 76:93-9.

2. Riboli E, Norat T. Epidemiologic evidence of the protective effect of fruit and vegetables on cancer risk. Am J Clin Nutr. 2003;78[Suppl 3]:559S-69S.

3. Joshipura KJ, Ascherio A, Manson JE, Stampfer MJ, Rimm EB, Speizer FE, et al. Fruit and vegetable intake in relation to risk of ischemic stroke. JAMA. 1999;282:1233-9.

4. Iso H, Kobayashi M, Ishihara J, Sasaki S, Okada K, Kita Y, et al. Intake of fish and $\mathrm{n} 3$ fatty acids and risk of coronary heart disease among Japanese: the Japan Public Health Center-Based (JPHC) Study Cohort I. Circulation. 2006;113:195-202.

5. Truswell AS. Practical and realistic approaches to healthier diet modifications. Am J Clin Nutr. 1998;67[Suppl 3]:583S-90S.

6. Ministry of Health, Labor and Welfare. The National Health and Nutrition Survey in Japan, 2008 (in Japanese). Tokyo: Daiichi Public; 2009.

7. National Agency for the Advancement of Sports and Health. Report on the children/students dietary situation survey, 2007 (in Japanese).. Tokyo: NAASH; 2008

8. Sjoberg A, Hallberg L, Hoglund D, Hulthen L. Meal pattern, food choice, nutrient intake and lifestyle factors in The Goteborg Adolescence Study. Eur J Clin Nutr. 2003;57:1569-78.

9. Utter J, Scragg R, Mhurchu CN, Schaaf D. At-home breakfast consumption among New Zealand children: associations with body mass index and related nutrition behaviors. J Am Diet Assoc. 2007;107:570-6.

10. Sasaki S, Shimoda T, Katagiri A, Tsuji T, Amano K. Eating frequency of rice vs. bread at breakfast and nutrient and foodgroup intake among Japanese female college students. J Community Nutr. 2002;4:83-9.

11. Videon TM, Manning CK. Influences on adolescent eating patterns: the importance of family meals. J Adolesc Health. 2003;32: 365-73.
12. Neumark-Sztainer D, Hannan PJ, Story M, Croll J, Perry C. Family meal patterns: associations with sociodemographic characteristics and improved dietary intake among adolescents. J Am Diet Assoc. 2003;103:317-22.

13. Lien N, Lytle LA, Klepp KI. Stability in consumption of fruit, vegetables, and sugary foods in a cohort from age 14 to age 21 . Prev Med. 2001;33:217-26.

14. Lytle LA, Seifert S, Greenstein J, McGovern P. How do children's eating patterns and food choices change over time? Results from a cohort study. Am J Health Promot. 2000;14:222-8.

15. Sasaki S. Development and evaluation of dietary assessment methods using biomarkers and diet history questionnaires for individuals. In: Tanaka H, editor. Research for evaluation methods of nutrition and dietary lifestyle programs held on healthy Japan 21: summary report (in Japanese). Tokyo: Ministry of Health, Welfare, and Labor of Japan; 2004. p. 10-44.

16. Okuda M, Sasaki S, Bando N, Hashimoto M, Kunitsugu I, Sugiyama $\mathrm{S}$, et al. Carotenoid, tocopherol, and fatty acid biomarkers and dietary intake estimated by using a brief selfadministered diet history questionnaire for older Japanese children and adolescents. J Nutr Sci Vitaminol (Tokyo). 2009;55:231-41.

17. Shunan City official website. Shisei jouhou (municipal government information), 30 September 2011. Available at: http:// www.city.shunan.lg.jp/section/shimin/jinkou.jsp. Accessed 15 Oct 2011

18. Atkinson FS, Foster-Powell K, Brand-Miller JC. International tables of glycemic index and glycemic load values: 2008. Diabetes Care. 2008;31:2281-3.

19. Nanri A, Mizoue T, Noda M, Takahashi Y, Kato M, Inoue M, et al. Rice intake and type 2 diabetes in Japanese men and women: the Japan Public Health Center-based Prospective Study. Am J Clin Nutr. 2010;92:1468-77.

20. Yokota K, Harada M, Wakabayashi Y, Inagawa M, Oshima M, Toriumi S, et al. Evaluation of a community-based health education program for salt reduction through media campaigns (in Japanese). Nippon Koshu Eisei Zasshi. 2006;53:543-53.

21. Swift PA, Markandu ND, Sagnella GA, He FJ, MacGregor GA. Modest salt reduction reduces blood pressure and urine protein excretion in black hypertensives: a randomized control trial. Hypertension. 2005;46:308-12.

22. Iso H, Shimamoto T, Naito Y, Sato S, Kitamura A, Iida M, et al. Effects of a long-term hypertension control program on stroke incidence and prevalence in a rural community in northeastern Japan. Stroke. 1998;29:1510-8.

23. Kusano-Tsunoh A, Nakatsuka $H$, Satoh H, Shimizu H, Sato S, Ito I, et al. Effects of family-togetherness on the food selection by primary and junior high school students: family-togetherness means better food. Tohoku J Exp Med. 2001;194:121-7.

24. Gillman MW, Rifas-Shiman SL, Frazier AL, Rockett HR, Camargo CA Jr, Field AE, et al. Family dinner and diet quality among older children and adolescents. Arch Fam Med. 2000;9: 235-40.

25. Larson NI, Neumark-Sztainer D, Hannan PJ, Story M. Family meals during adolescence are associated with higher diet quality and healthful meal patterns during young adulthood. J Am Diet Assoc. 2007;107:1502-10.

26. Sweeting H, West P. Dietary habits and children's family lives. J Hum Nutr Diet. 2005;18:93-7.

27. Serra-Majem L, Ribas L, Ngo J, Ortega RM, Garcia A, PerezRodrigo C, et al. Food, youth and the Mediterranean diet in Spain. Development of KIDMED, Mediterranean Diet Quality Index in children and adolescents. Public Health Nutr. 2004;7:931-5.

28. Boutelle KN, Birkeland RW, Hannan PJ, Story M, NeumarkSztainer D. Associations between maternal concern for healthful eating and maternal eating behaviors, home food availability, and adolescent eating behaviors. J Nutr Educ Behav. 2007;39:248-56. 